\title{
Five short lemmas in Banach spaces
}

\section{QINGPING ZENG}

\section{ABSTRACT.}

Consider a commutative diagram of bounded linear operators between Banach spaces

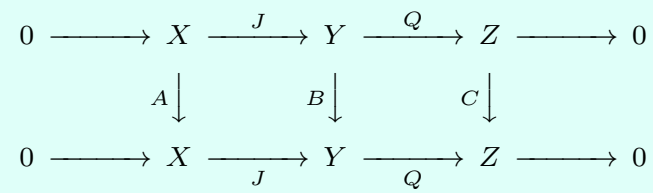

with exact rows. In what ways are the spectral and local spectral properties of $B$ related to those of the pairs of operators $A$ and $C$ ? In this paper, we give our answers to this general question using tools from local spectral theory.

Acknowledgement. This work has been supported by National Natural Science Foundation of China $(11401097,11171066,11201071,11301077,11301078)$.

\section{REFERENCES}

[1] Aiena, P., Fredholm and Local Spectral Theory, with Application to Multipliers, Kluwer Academic Publishers, Dordrecht, 2004

[2] Burgos, M., Kaidi, A., Mbekhta, M., and Oudghiri, M., The descent spectrum and perturbations, J. Operator Theory, 56 (2006), 259-271

[3] Dowson, H. R., Spectral Theory of Linear Operators, Academic Press, New York, 1978

[4] Finch, J., The single valued extension property on a Banach space, Pacific J. Math, 58 (1975), 61-69

[5] Laursen, K. B. and Neumann, M. M., An Introduction to Local Spectral Theory, Oxford University Press, 2000

[6] Mbekhta, M., Généralisation de la décomposition de Kato aux opérateurs paranormaux et spectraux, Glasg. Math. J., 29 (1987), 159-175

[7] Oudghiri, M., a-Weyl's theorem and perturbations, Studia Math., 173 (2006), 193-201

[8] Zeng, Q. P. and Zhong, H. J., Three-space theorem for semi-Fredholmness, Arch. Math., 100 (2013), 55-61

FUIIAN AGRICULTURE AND FORESTRY UNIVERSITY

COLLEGE OF COMPUTER AND INFORMATION SCIENCES

350002 FuZHOU, P. R. CHINA

E-mail address: zqpping2003@163.com

Received: 16.01.2014; In revised form: 20.03.2015; Accepted: 27.03.2015

2010 Mathematics Subject Classification. 47A10, 47A11, 47A53.

Key words and phrases. Short five lemma, Bishop's property, single valued extension property, Drazin invertible, spectrum. 